\title{
The Relationship between Teamwork and the Performance of Medical Staff of Shahid Rajaei Cardiovascular, Medical and Research Center in
}

\author{
Tehran, Iran in 2016
}

\author{
Farahnaz Mirzaei ${ }^{1}$, Seyed Jamaleddin Tabibi ${ }^{2}$, Leila Nazarimanesh ${ }^{3}$
}

\begin{abstract}
Background \& Aims: The present study aimed to evaluate the relationship between teamwork and performance of the medical staff of Shahid Rajaei Cardiovascular, Medical and Research Center in Tehran, Iran. In a health system, teamwork is highly important for increasing the quality of services and the provision of safe and effective care. In addition, teamwork is recognized as an integral part of safe and efficient performance in a hospital. In addition, patient safety and health are considered a critical issue in the health systems of various countries. Therefore, teamwork and communication to prevent and reduce the medical staff's errors are of utmost importance. The present study was carried out to assess the relationship between the teamwork of nurses and the performance of the medical staff of Shahid Rajaei Cardiovascular, Medical and Research Center in Tehran.

Materials \& Methods: This descriptive-analytical research was performed in 2016. The statistical population included all nurses with a BSc, MSc, or higher degree working at medical centers of the university $(n=290)$. The present research was carried out as correlational research, which is a type of descriptive study (nonexperimental) that evaluates the relationship among variables based on research objectives. In total, 290 individuals were selected by simple non-random sampling method, and data were collected using a staff performance questionnaire by Choharie et al. and a teamwork questionnaire by Luncheon. The validity and reliability of the researcher-based questionnaire used in the present study were confirmed, and data analysis was performed in SPSS version 16 using the Pearson correlation coefficient and t-test.

Results: In the evaluation of the correlation of two variables, the Pearson correlation coefficient will be applied if both variables are in relative and distance scale. If the correlation coefficient of the population is $\rho$ and the correlation coefficient is a sample with $\mathrm{n}$ volume of the population $\mathrm{r}, \mathrm{r}$ might be obtained randomly. To this end, we exploited the significance test of the correlation coefficient to determine whether the two variables were random or independent. In other words, the question was: are the correlation coefficient of community zero or not. The coefficient estimates the level of correlation between two distance or relative variables with a value in the range of +1 and -1 . A positive value is interpreted as changes occurred in the two variables in the same direction. In other words, an increase in one variable leads to an increase in the other variable. On the other hand, a negative $r$ value means that the two variables operate in the opposite direction. In other words, an increase in the value of one variable decreases the value of the other variable and vice versa. In addition, a zero value shows the lack of relationship between the two variables, whereas a positive and negative value is indicative of a completely positive and completely negative correlation, respectively. In the present study, the mean and standard deviation of the components of teamwork and performance of the staff was estimated at 3.28 \pm 0.69 and $3.64 \pm 0.55$, respectively. Moreover, the mean of dimensions of commitment, trust, accountability, constructive approach, and purposefulness was reported to be $3.21 \pm 0.75,3.18 \pm 0.84,3.18 \pm 0.80,3.34 \pm 0.75$, and 3.54 \pm 0.90 , respectively. According to the Pearson correlation coefficient, there was a direct and significant relationship between the performance of the staff and teamwork among clinical employees $(0.514<\mathrm{r}<0.651$; $\mathrm{P}<0.05)$.

Conclusion: According to the analysis performed, teamwork is a dynamic process, which includes two or several professional members sharing common treatment goals, necessary health skills, and specialties, who

\footnotetext{
1. Health Services Management, Department of Management, Islamic Azad University, Science and Research Branch, Tehran, Iran

2. School of Medical's Science \& Technology, Islamic Azad University, Science and Research Branch, Tehran, Iran (Corresponding author) Tel:091211033551 Email: j-tabibi@srbiau.ac.ir

${ }^{3}$. School of Medical's Science \& Technology, Islamic Azad University, Science and Research Branch, Tehran, Iran
} 
work with each other in an intimate working environment for solving specific and common goals. Team processes are a vital component of forming a coherent, committed, and united treatment team. Every year, healthcare providers are expected to use fewer employees with higher treatment safety. The importance of having a robust medical team and teamwork is highlighted due to the shortage of personnel and educational costs, medical errors, and increasing patient expectations. Teamwork in the healthcare field is so crucial that numerous studies have been conducted on training medical staff and team-making topics. It is notable that the organizations that apply teamwork have experienced significant improvement in their staff's creativity, productivity, and satisfaction. According to the results, the level of teamwork among the staff was above average. Nonetheless, their teamwork should be enhanced to reach higher levels. In addition, managers in various sectors and hospital management should pay more attention to people's achievements and use their opinions. Moreover, they should teach teamwork and related skills to their staff and use the necessary control levers in group management. All of these measures will ultimately lead to reduced possibility of rehospitalization, decreased duration of hospital stay, and improved safety and performance results of the medical staff. Teamwork is not the regular placement of individuals in a specific location. In fact, teamwork requires adapting to each other's performance, understanding the treatment needs, being able to anticipate the priorities of others, and acclimating to changes in the environment. In addition, teamwork is required for better patient management and establishment of treatment safety.

The results were indicative of a significant relationship between teamwork and performance of the medical staff of Shahid Rajaei Cardiovascular, Medical and Research Center in Tehran with the components of commitment (coefficient of), trust (coefficient of 0.79), accountability (coefficient of 0.84), constructive approach (coefficient of 0.77), and purposefulness (coefficient of 0.78). furthermore, strengthening teamwork among various employees and establishing educational workshops on communication skills can contribute to the improvement of staff's performance.

\section{Keywords: Teamwork, Performance, Medical Staff, Cardiovascular Hospital}

\section{Conflict of Interest: No}

How to Cite: Mirzaei F, Tabibi SJ, Nazarimanesh L. The Relationship between Teamwork and the Performance of Medical Staff of Shahid Rajaei Cardiovascular, Medical and Research Center in Tehran, Iran in 2016. Iran Journal of Nursing. 2020; 33(125):70-8.

Received: 13 May 2020

Accepted: 15 Aug 2020 


\section{ارتباط كار تروهى با عملكرد كار كنان درمانى مركز آموزشى تحقيقاتى و درمانى قلب و عروق شهيد رجايى تهران در سال هون}

فرحناز ميرزايى '، سيد جمال الدين طبيبى '، ليلا نظرى منش؟

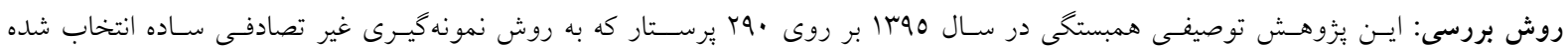

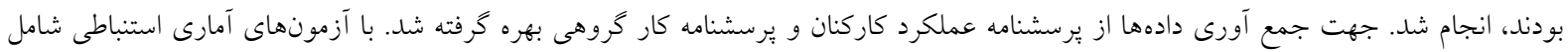

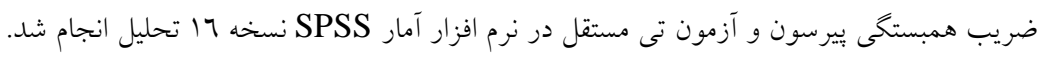

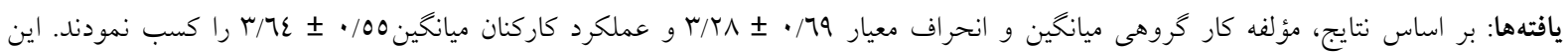

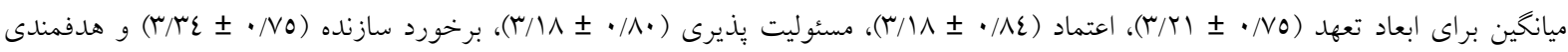

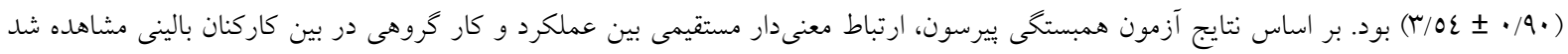
$(\cdot / 01 \varepsilon<\mathrm{r}<\cdot / 701 \mathrm{p}<\cdot / \cdot 0)$

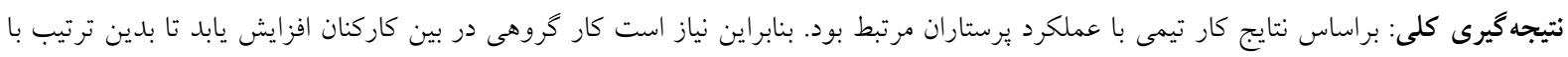

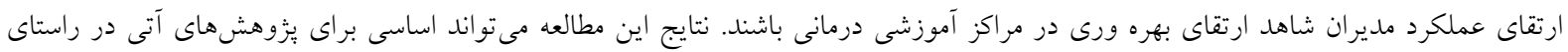
ارتقاى كارگروهى و عملكرد يرستاران باشد.

كليد وازهها: كار گروهى، عملكرد، كاركنان بالينى، بيمارستان قلب

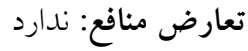
تاريخ دريافت: ع ع 99/T/ تاريخ بذيرش: 99/0/Y0

'. مديريت خدمات بهداشتى و درمانى، كروه مديريت، دانشعاه آزاد اسلامى واحد علوم تحقيقات، تهران، ايران

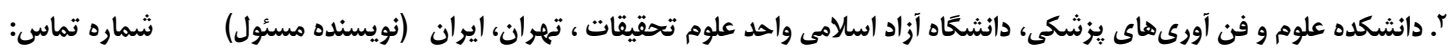
Email: j-tabibi@srbiau.ac.ir

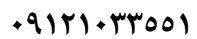
". دانشكده علوم و فن آورىهاى يزشكى، دانشًاه آزاد اسلامى واحد علوم تحقيقات ، تهران، ايران 
كار گروهى در حوزه بهداشت و درمان تا به آن جا است

كه يُزوهش هاى بسيارى در نقاط مختلف جهان در زمينه

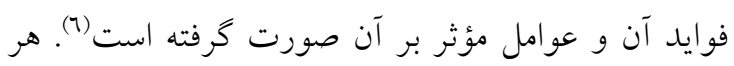
ساله از ارائه دهندگان مراقبت بهداشتى انتظار مىرود كه با تعداد كمتر و با امنيت بالاترى كار كنند. كار گروهى مؤثر به عنوان راه حلى براى مقابله با رشد فزاينده كمبود كاركنان و هزينههاى آموزشى، افزايش انتظارات بيماران و

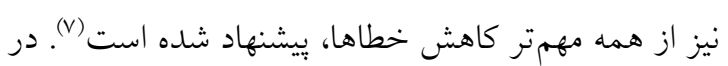
سه دهه اخير تالشهاى فراوانى در كشورهاى توسعه يافته به ويزه ايالات متحده، انخلستان و كانادا صورت كرفته است تا آموزش علوم يزشكى و همجنين آموزش مداوم جامعه يزشكى، هر جّه بيشتر با مفهوم مشاركت و كار كروهى به عنوان يكى از كليدىترين راهكارهاى ارتقاى كيفيت خدمات بهداشتى درمانى در بين اعضاى تيم

$$
\text { سلامت عجين گردد (^). }
$$

بيمارستانها به عنوان مهمترين نهاد ارائه خدمت در نظام هاى سلامت شناخته مىشوند كه بخش اعظم نيروى انسانى، بودجه و حجم خدمات ارائه شده در اين بخش را به خود اختصاص مىدهند. خدمات بيمارستانى در حدود •0 تا • م درصد بودجه بخش سلامت و سهم عظيمى از نيروهاى آموزش ديله و متخصص را به خود اختصاص مىدهد. نيروى انسانى در زمره مهمترين منابع بيمارستانى

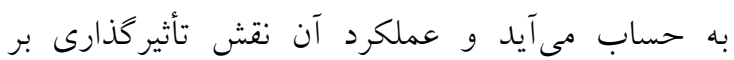
كيفيت ارائه خدمات دارد(9). عدم عملكرد مناسب منابع انسانى بيمارستان باعث محدوديت در ارائه و كيفيت خدمات سلامت خواهد شد(·). از سوى ديخر، مطالعات مختلف نشان دادهاند كه بهبود عملكرد كاركنان بيمارستانى ضامن بهره ورى سازمان و افزايش پِاسخخويى آن است(11). علاوه بر اين، ارتقا عملكرد كاركنان موجب لئب ارائه خدمات با كيفيت، اثربخش و كاراست و در نهايت رضايت بيماران را در ييى دارد(rا). به طور سنتى يزشكان، يرستاران و ديخر حرفههاى مراقبت سلامت، هميشه به عنوان بخشهاى مجزا عمل كردهاند و با وجود اهميت كار گروهى در مراقبت سلامت بيشتر
در دو دهه اخير، سازمانها به طور جشمخيرى تغيير كردهاند. يكى از قابل توجهترين اين تغييرات، تغيير از سمت كار به صورت انفرادى به كار بر مبناى گروه است. دوران كنونى، دوران تخصصهاى متفاوت است. امروز ديخر يك نفر تنها به صرف اين كه در يك رشته تخصص دارد نمىتواند در فعاليتهاى مختلف آموزشى، تجارى، اقتصادى و درمانى موفق باشد. به عبارت ديخر، دنياى امروز دنياى تشكيل گروههاى كارى است و اخر در هر بر بـ مؤسسه يا سازمان افراد موفق به كار گروهى نشوند، شركت و سازمان، يكى از كليدهاى مهم موفقيت را از دست داده است. تمركز و توجه بر اثربخشى و كار آمدى كروههاى كارى، مستلزم داشتن روحيه كار كروهى است(1). امروزه شركتها و سازمانهايى كه به موفقيت مى انديشند، نه تنها در بخشهاى مختلف خود كار كروهى را به عنوان يكى شيوه سازماندهى به كار مىبرند

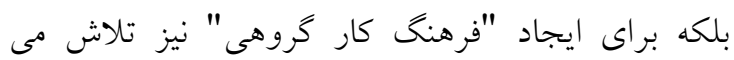
كنيل (r) اثر قابل ملاحظه فرهنخ كار گروهى و كار گروهى، آن

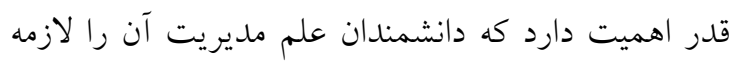
دست يافتن به قابليتهاى محورى يايدار (مزيت رقابتى يايدار) در فضاى رقابتى دنياى امروز مىدانند (r). در دو دهاى اخير، بسيار بر اهميت كار گروهى براى موفقيت سازمانها در كنار عوامل فردى و سازمانى تأكيد شده بـ بره است. همين امر باعث شده مطالعات زيادى در اين زمينه

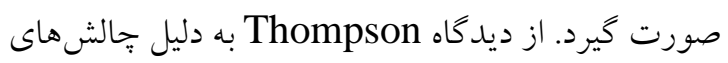
جهان آينده، تشكيل و نخهدارى گروههاى كارى براى سازمانها امرى لازم و ضرورى است استهان. امروزه ارايه مراقبتهاى سلامت با كيفيت، نيازمند تعداد زيادى از شاغلين ماهر با تخصص هاى مختلف است كه به طور مؤثرى با يكديخر همكارى مى كنند. در واقع مراقبتهاى سلامت به صورت تالش گروهى انكارنايذير بوده و هيج فردى نمىتواند به تنهايى زنجيره ارائه خدمات مراقبت هاى سلامتى را تكميل نمايد (0) اهميت 
اين بررسى به روش توصيفى از نوع همبستكى صورت

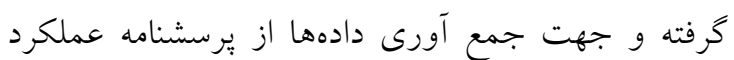

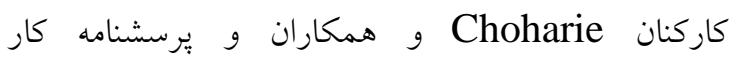
تيمى Luncheon بهره كرفته شده و براى تجزيه و و

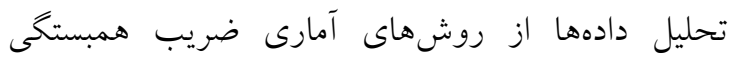

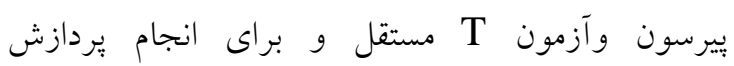
اطلاعات از نرم افزار آمارى SPSS نسخه 17 استفاده شده است. جامعه آمارى اين تحقيق را تمامى بِرستاران و كادر درمانى كه داراى مدرك تحصيلى ليسانس به بالاتر مى باشند، تشكيل مىدهند و حجم نمونه مورد يزوهش تعداد . انتخاب شدهاند. جهت گردآورى دادهها، ابزار مورد استفاده برسشنامهاى

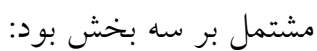
بخش اول: شامل اطلاعات جمعيت شناختى كاركنان از قبيل سن، جنسيت، وضعيت تأهل، سابقه كارى، سال، تحصيلات و وضعيت استخدامى مىباشد.

Choharie بخش دوم: شامل برسشنامه عملكرد كاركنان

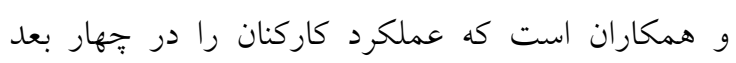
خدمت به مشترى (9 سؤال)، بهره ورى (7 سؤ ال)، كيفيت

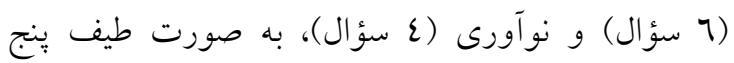

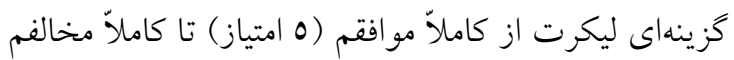

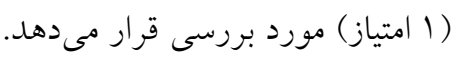
بخش سوم: برسشنامه كار تيمى Luncheon بهره كرفته

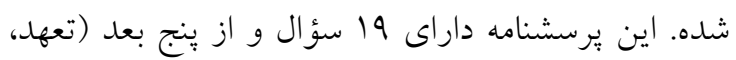

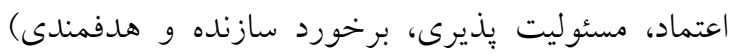
تشكيل شده است و بر اساس طيف ينج گزينهاى ليكرت

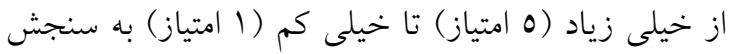
كار گروهى مى يردازد. محاسبه ضريب پايايى ابزار، آلفاى

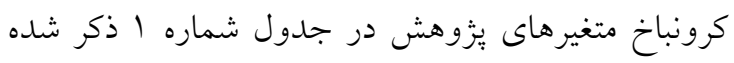

واحدهاى بالينى به عنوان مجموعهاى از حرفههاى

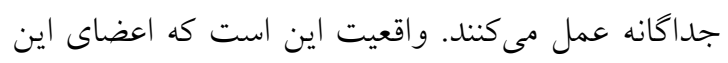

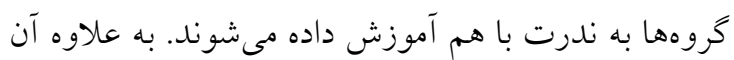

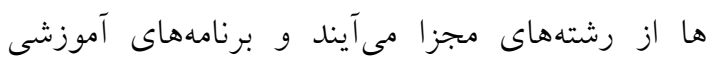

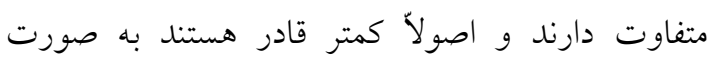

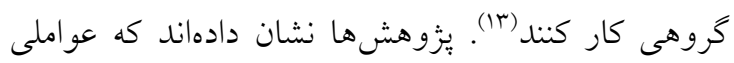
مانند غـرور، حسـادت، تـرس از بـهـ تهلديــ افتـادن

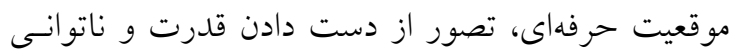
در برقرارى ارتباط و همكارى مؤثر با ديخران از جمله

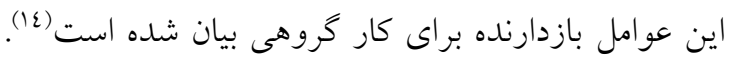

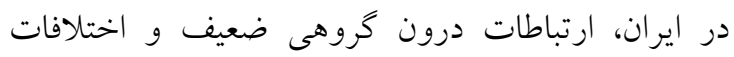

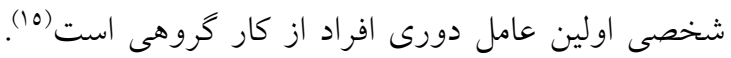

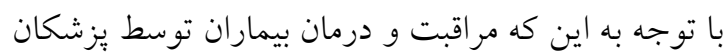

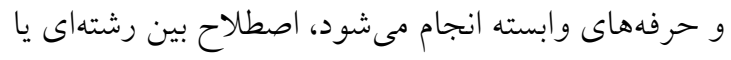

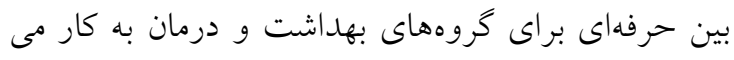

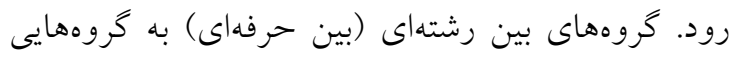

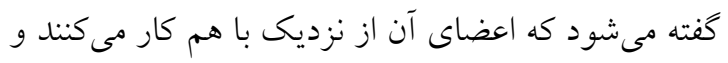

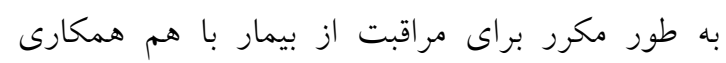
دارند (17).

بنابراين با توجه به اهميت مسئله عملكرد كاركنان بالينى

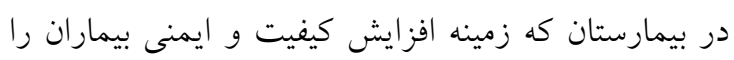
به دنبال دارد، يرداختن به عواملى كه باعث بهبود و تسهيل

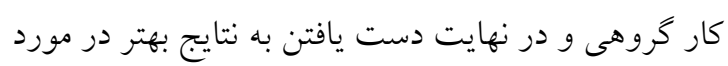

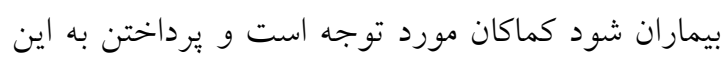
مسئله به صورت يكى امر ضرورى نمود ييدا مى بكند.

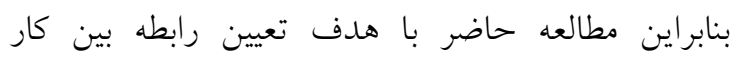
كروهى و عملكرد كاركنان بالينى بيمارستان قلب شهيد رجائى به انجام رسيد.

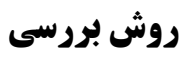




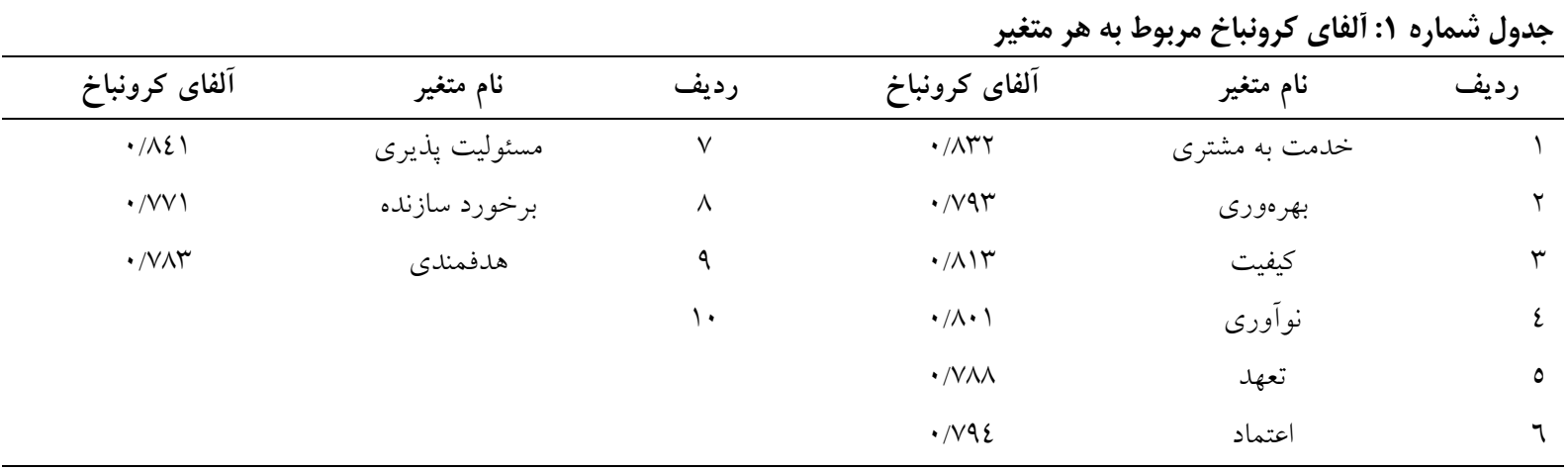

(SRB.REC.1397.094 و مكاتبات لازم جهت

هماهنكى با بيمارستان، تكميل : يرسشنامها توسط

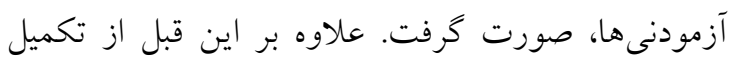

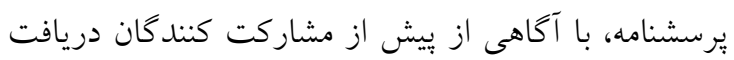

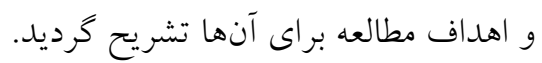

\section{يافتهها}

نتايج تحقيق در بخش توصيفى در جدول شماره Y مورد بر بـى قرار كرفته است.
بعد از گردآورى برسشنامههاى تكميل شده، براى تجزيه

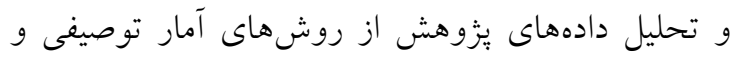

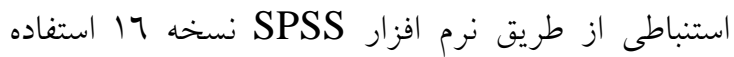

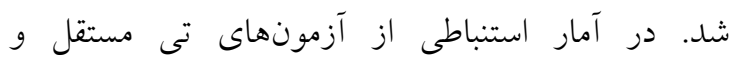
همبستخى بيرسون با سطح معنى دارى 0٪

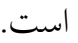
در نهايت ڤّ از كسب مجوزهاى لازم از معاونت

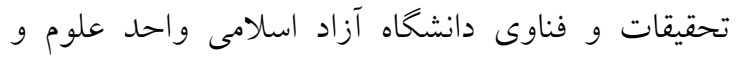

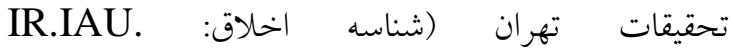

جدول شماره ז: فراوانى متغيرهاى جمعيت شناختى كار كنان بالينى مورد مطالعه

\begin{tabular}{|c|c|c|c|}
\hline درصد & فراوانى (درصد) & نوع & متغيير \\
\hline ऍN/ & 115 & $r \cdot-r$. & \\
\hline $\mathrm{ru} / \mathrm{T}$ & $1 \cdot 7$ & $\mu \cdot-\varepsilon$. & سن، سال \\
\hline$r T / I$ & $7 \varepsilon$ & $\varepsilon \cdot-0$. & \\
\hline$r / \Lambda$ & $\wedge$ & $7 \cdot-0$. & \\
\hline$\mu$. & $\Lambda V$ & مرد & جنسيت \\
\hline$V \cdot$ & $r \cdot r$ & زن & \\
\hline$\varepsilon 1 / V$ & $|r|$ & مجرد & وضعيت تأهل \\
\hline$O N / r$ & 179 & متأهل & \\
\hline $0 \varepsilon / \Lambda$ & 109 & $1-1$. & \\
\hline & 91 & $11-r$. & سابقه كارى، سال \\
\hline $11 / 2$ & rr & $r \cdot-r$. & \\
\hline Vo/o & $Y 19$ & ليسانس & \\
\hline $10 / r$ & $\varepsilon \varepsilon$ & فوق ليسانس & تحصيلات \\
\hline $9 / \mu$ & TV & د د & \\
\hline$\varepsilon \varepsilon / \Lambda$ & ir. & رسمى & \\
\hline $1 \% / \Lambda$ & $\varepsilon$. & بيمانى & وضعيت استخدامى \\
\hline$r T / r$ & VI & قراردادى & \\
\hline$\varepsilon / 0$ & $1 r$ & شركتى & \\
\hline $1 \cdot / V$ & M & طرحى & \\
\hline
\end{tabular}


بالينى، مناسب مىباشد بر اين اساس ميانخين كل عملكرد در بررسى وضعيت كار گروهى كاركنان بالينى و با توجه عَآ به دست آمد. (جدول شماره بال).

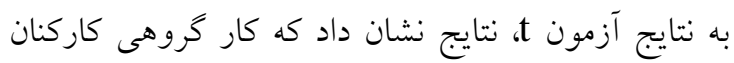

جدول شماره با: بررسى وضعيت كار تَروهى و عملكرد كاركنان بالينى مورد مطالعه

\begin{tabular}{|c|c|c|c|c|c|c|c|}
\hline \multicolumn{7}{|c|}{ ارزش آزمون (Test Value) } & (2) \\
\hline \multicolumn{2}{|c|}{ فاصله اطمينان (90/.٪) } & \multirow{2}{*}{ ميانخين اختلاف } & \multirow[t]{2}{*}{$\mathrm{P}$ value } & \multirow[t]{2}{*}{$\mathrm{df}$} & \multirow[t]{2}{*}{$\mathrm{t}$} & \multirow[t]{2}{*}{ ميانخين } & \multirow[t]{2}{*}{ كار خروهى كاركنان بالينى } \\
\hline 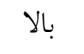 & بايين & & & & & & \\
\hline$\cdot / \pi 7$ & $\cdot \pi \cdot$ & $\cdot / \Gamma \wedge$ & $=\cdot / \cdot r V p$ & r^q & $7 / 9$. & $r / \Upsilon \Lambda$ & تعهد كاركنان بالينى \\
\hline$\mu$. & $\cdot / r$ & $\cdot / r 1$ & $=\cdot / \cdot r r p$ & r^q & $\varepsilon / \wedge \varepsilon$ & $r / r)$ & اعتماد كار كنان بالينى \\
\hline$\cdot / r \Lambda$ & $\cdot / \cdot 1$ & $\cdot / \Lambda$ & $=\cdot / \cdot \varepsilon r p$ & 119 & $r / v \cdot$ & $r / \Lambda$ & مسئوليت بذيرى كاركنان بالينى \\
\hline$\cdot / T V$ & $.1 \cdot 9$ & $\cdot / \Lambda$ & $=\cdot / \cdot \varepsilon \varepsilon p$ & r^q & $r / \Lambda V$ & $\Upsilon / \Lambda$ & برخورد سازنده كاركنان بالينى \\
\hline$\cdot / \varepsilon r$ & $\cdot /$ TO & $\pi \varepsilon$ & $=\cdot / \cdot r v p$ & r^q & $\mathrm{V} / \mathrm{T} \Lambda$ & $r / \mu \varepsilon$ & هدفمندى كار كنان بالينى \\
\hline
\end{tabular}

كه كار گروهى و ابعاد آن با عملكرد رابطه دارد، تأييد مى گردد.
بر اساس جدول شماره ع و با توجه به نتايج به دست

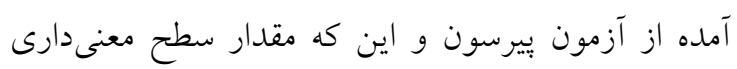

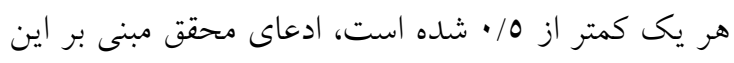

جدول شماره ع: محاسبه همبستخى عملكرد با كار تروهى

\begin{tabular}{|c|c|c|}
\hline \multicolumn{2}{|c|}{ همبستخى بيرسون } & \multirow[t]{2}{*}{ مؤلفهها } \\
\hline معنى دارى & ضر يب همبستخى & \\
\hline $\mathrm{p}<\cdot / \cdots 1$ & $\cdot / 701$ & عملكرد **كار گروهى \\
\hline $\mathrm{p}<\bullet / \cdots 1$ & $\cdot / 0 \mathrm{VV}$ & عملكرد ** تعهد كاركنان بالينى \\
\hline $\mathrm{p}<\cdot / \cdots 1$ & . - ( & عملكرد ق* اعتماد كاركنان بالينى \\
\hline $\mathrm{p}<\cdot / \cdots)$ & $\cdot / 0 \mu_{1}$ & عملكرد ** مسئوليت يذيرى كاركنان بالينى \\
\hline $\mathrm{p}<\cdot / \cdots 1$ &.$/ 01 \varepsilon$ & عملكرد ** برخورد سازنده \\
\hline
\end{tabular}

يافتهاى يُزوهش: بر اساس نتايج حاصله با مؤلفهاى بحث و نتيجه كيرى

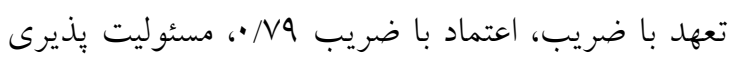
هدف از اين ئزوهش بررسى ارتباط كار كروهى با باري

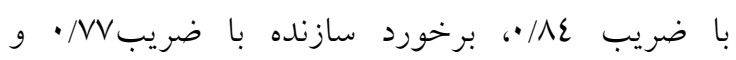

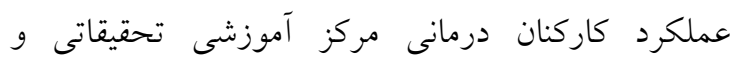

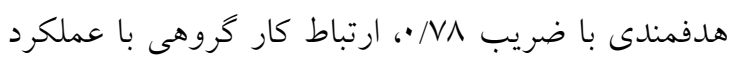
درمانى قلب و عروق شهيد رجايى تهران مىباشد. از آن آن

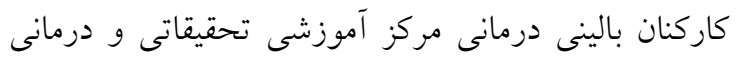
قلب و عروق شهيد رجايى رابطه معنى دارى را نشان داد.

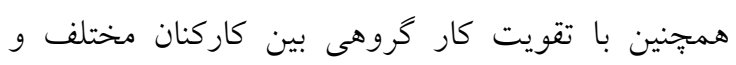

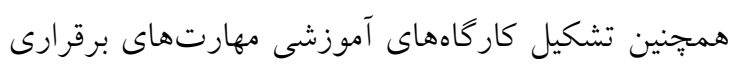

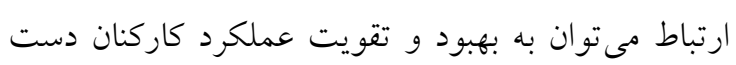
جايى كه كليد اصلى موفقيت و اثربخشى سازمانها در

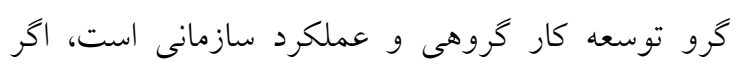
قصد بر اين است كه كار گروهى و عملكرد سازمانى افراد وند

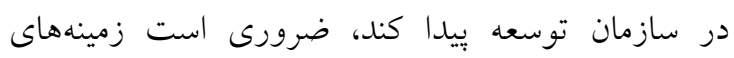

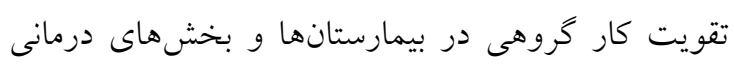

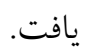

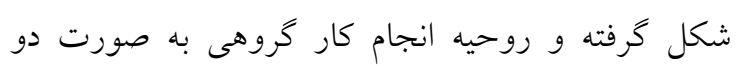

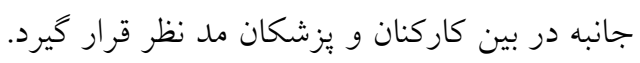


با توجه ببه يافتهها و نتايج تحقيق، بيشنهادات ذيل به مديران مركز آموزشى تحقيقاتى و درمانى قلب و عروق

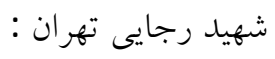
از طريق ايجاد جو اعتماد بين مديران و كاركنان درمانى (كار گروهى)، شفافيت در شرح وظايف و مسئوليتها، واگذارى اختيارات لازم جهت تصميم گيرى و ياسخخويى در برابر نتايج، استقلال و آزادى لازم در جّحونكى انجام وظايف به كادر درمان كه موجب افزايش رضايت شغلى مى شود. جهت افزايش رضايت شغلى كادر بيرستار، مديران بيمارستان تمركز بيشترى را بر روى كارتيمى به منظور افزايش دانش و مهارت كادر درمانى كه براى افزيش عملكرد سازمانى لازم خواهد بود، در دستور كار قرار دهند. مديران بيمارستان به طور مداوم بر برنامههاى آموزشى تمركز ويزه داشته باشند به خصوص براى كاركنان تازه استخدام شده در بخش درمان، زيرا افزايش آكاهى و و شناخت در مورد نحوه انجام كار، در افزايش انخيزه و رضايت كاركنان درمان بسيار مؤثر است.

تعارض منافع: نويسندگان هيج گونه تعارض منافعى را كزارش نكردهاند.

\section{تقدير و تشكر}

تشكر فراوان از استاد ارجمند دكتر طيبى بزرگوار كه در

$$
\text { همه مراحل راهنماى اينجانب بودند. }
$$

تتايج مطالعه بيك زاد و همكاران در بين يرستاران شاغل در بيمارستانهاى آموزشى تبريز نشان داد مسئوليت يذيرى تأثيرى مثبتى بر خشنودى شغلى و در نهايت افزايش بهره ورى و عملكرد يرستاران دارد(IV). و همجنين مطالعه Frolula و Lapina بيان مىدارد كه ونه مسئوليت يذيرى كاركنان موجب كاهش هزينهها در درازملت و افزايش كيفيت فرآيندها و در نهايت بهبود عملكرد كلى مى گردد (1). در صورتى كه مسئوليت يذيرى كاركنان به خصوص در بيمارستان به عنوان يك سازمان حساس و مهم كه با جان انسانها سرو كار دارد بالا باشد موجب مى گردد تا شوق و علاقه اعضاى تيم بـ بازخواست كردن خود و همتايان درباره رفتار يا عملكردى كه براى تيم زيان بار است بالا باشد. اين مهم خود موجب كاهش و اصلاح بسيارى از خطاها و اشتباهات مى كردد. نتايج حاكى از آن است كه سطح كار كروهى در بين كاركنان بالاتر از حد ميانخين است. با اين وجود مى لى بايست تقويت شده و به سطوح بالاترى برسد. مديران بخشهاى مختلف و نيز مديريت بيمارستان مىبايست به

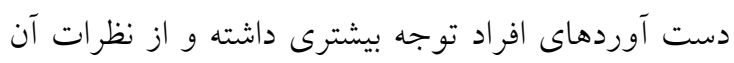
ها بهره مند گردند، كار گروهى و مهارتهاى مربوط به آن را به كاركنان آموزش دهند و در نهايت از اهرمهاى كتترلى لازم در مديريت كروهها بهره ببرند. اين موارد در نهايت منجر به كاهش احتمال بسترى مجدد، كاهش زمان اقامت و ارتقاء سطح ايمنى و در كل بهبود نتايج عملكردى مى گردد.

\section{References}

1. Ebrahimi A, Mirtorabi m. Team and team work. Agricultural and Natural Resources Engineering Disciplinary Organization. 2012;7(27):45-52. [Persian]

2. Körner M, Wirtz MA, Bengel J, Göritz AS. Relationship of organizational culture, teamwork and job satisfaction in interprofessional teams. BMC health services research. 2015;15(1):243.

3. Hollenbeck JR, Noe RA, Gerhart BA. Human resource management: Gaining a competitive advantage. McGraw-Hill Education; 2018.

4. Thompson LL, Thompson M. Making the team: A guide for managers: Pearson Prentice Hall Upper Saddle River, NJ;2008. 
5. O'leary KJ, Sehgal NL, Terrell G, Williams MV, High Performance Teams and the Hospital of the Future Project Team. Interdisciplinary teamwork in hospitals: a review and practical recommendations for improvement. J Hosp Med. 2012;7(1):48-54.

6. Eldar R, Marincek C, Kullmann L. Need for rehabilitation teamwork training in Europe. Croat Med J. 2008;49(3):352-7.

7. Azimi Lolaty H, Ashktorab T, Bagheri Nesami M, Bagherzadeh Ladari R. Experience of professional communication among nurses working in educational hospitals: a phenomenological study. Journal of Mazandaran university of medical sciences. 2011;21(85):108-25. [Persian]

8. Ravanipour M, Yazdankhahfard M, Akaberian S, Bahreini M. Teamwork concept in nursing students' point of view at bushehr university of medical sciences. Educational Development of Judishapur. 2014;5(3):266-75. [Persian]

9. Sadeghifar J, Pourreza A, Ahmadi B, Zeraati H, Arab M. Assessment of necessary staff for hospitals of Ilam university of medical sciences in accordance with personnel criteria and standards of Iranian health ministry. 2011. [Persian]

10. Najafi H, Khaleghkhah A. The impact of organizational silence on organizational performance (Case study: Nurses of Mazandaran Bo-Ali-Sina hospital). Iranian Journal of Nursing Research. 2017;12(5):45-52. [Persian]

11. Moheb m, Masoud F, Haghighat M, Rajalian F. Prioritizing key indicators of human resource performance using multivariate decision making techniques in selected hospitals of Isfahan University of Medical Sciences. Journal of Health Management. 2015;6(1):43-50. [Persian]

12. Rahmani H, Rajabi Vasokolaee G, Saeidpour J, Rezaei M, Niakan S, Khosravi B. Pathology of human resources in Imam Khomeini hospital complex based on applying three-dimensional model. Journal of Hospital. 2018;16(4):35-41. [Persian]

13. Baker DP, Day R, Salas E. Teamwork as an essential component of high-reliability organizations. Health Serv Res. 2006;41(4p2):1576-98.

14. Kalisch BJ, Lee KH. Variations of nursing teamwork by hospital, patient unit, and staff characteristics. Appl Nurs Res. 2013;26(1):2-9.

15. Behnia O, HosseinPour M, Zarea K. The analysis of the team working facilitating factors among nurses working in training centers affiliated with the University of Jondi SHapour in Ahvaz. Avicenna J Nurs Midwif Care. 2016;24(4):247-55.

16. Hall P. Interprofessional teamwork: Professional cultures as barriers. J Interprofessional care. 2005;19(sup1):188-96.

17. Beikzad J, Hoseinpour A, Hejazi Bavil M. A survey on the relationship between responsibility and job satisfaction of nurses working in teaching hospitals affiliated with Tabriz University of Medical Sciences. Journal of Hospital. 2014;13(1):53-60. [Persian]

18. Frolova I, Lapina I. Corporate social responsibility in the framework of quality management. Procedia-Social and Behavioral Sciences. 2014;156:178-82.

19. Walker IA, Reshamwalla S, Wilson IH. Surgical safety checklists: do they improve outcomes?. Br J Anaesth. 2012;109(1):47-54.

20. Undre S, Sevdalis N, Healey AN, Darzi A, Vincent CA. Observational teamwork assessment for surgery (OTAS): refinement and application in urological surgery. World journal of surgery. 2007;31(7):1373-81. 